\title{
A Congolese infant of 4 months and 8 days presenting a severe form of Covid-19
}

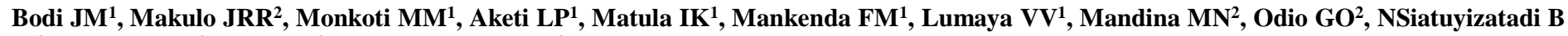 \\ $\mathbf{M}^{2}$, Tshibasu FT ${ }^{3}$, Lelo MT ${ }^{3}$, Bemba Nzuzi Joelle ${ }^{4}$ \\ ${ }^{1}$ Department of pediatrics, Kinshasa University Hospital, School of medicine, Kinshasa University. \\ ${ }^{2}$ Department of Internal Medicine, Kinshasa University Hospital, School of medicine, Kinshasa University, Center of Covid19 treatment. \\ ${ }^{3}$ Department of Internal Medicine, Service of Radiology, Kinshasa University Hospital, School of medicine, Kinshasa University. \\ ${ }^{4}$ Medical doctor, Department of pediatrics, University of Kinshasa, Republic Democratic of Congo.
}

*Corresponding Author: Joseph M Bodi, Department of pediatrics, Kinshasa University Hospital, School of medicine, Kinshasa University.

Received date: December 22, 2020; Accepted date: January 29, 2021; Published date: March 23,2021

Citation: Bodi JM, Makulo JRR, Monkoti MM, Aketi LP, Matula IK. (2021) A Congolese infant of 4 months and 8 days presenting a severe form of Covid-19. Biomedical Research and Clinical Reviews. 3(4); DOI: 10.31579/2692-9406/038

Copyright: ( $) 2021$ Joseph M Bodi, This is an open-access article distributed under the terms of the Creative Commons Attribution License, which permits unrestricted use, distribution, and reproduction in any medium, provided the original author and source are credited.

\begin{abstract}
To date, only a few rare cases of severe forms of Covid-19 in children, especially infant, have been described in other parts of the world. So far no case reported in sub-Saharan Africa (SSA). We report the case in the Democratic Republic of Congo of an infant of 4 months and 8 days old, who presented after malaria disease, a picture of bronchopneumonia with severe respiratory failure ( $\mathrm{Pa} \mathrm{O} 2: 49 \mathrm{mmHg}$ ). The RT-PCR made it possible to diagnose a Covid-19 of severe form. The infant had probably been infected by his mother and had no other co-morbidities that could induce a decrease in immunity. The CT scan injuries were comparable to those described in adults. Under oxygen, anticoagulation, hydroxychloroquine and Azythromycin, the outcome was good. Pediatricians in SSA countries should be careful and not miss cases of COVID19 in infant population with severe respiratory syndrome usually observed in most of lung infectious disease.
\end{abstract}

Keywords: Covid 19; severe form; infant; sub-Saharan Africa; DR Congo;

\section{Introduction}

Several data around the world show that the effects of the new pandemic of COVID-19 are less of a concern in children, who seem to be asymptomatic or to develop mild illness [1-3]. The reasons justifying this relative protection of children are not fully understood. However, most studies suggest that in rare severe forms of Covid-19 in children, the same risk factors in adults are evoked to children, including comorbidities such as cardiac pathology, diabetes, chronic pulmonary disease, HIV and druginduced immunosuppression [4]. In sub-Saharan Africa (SAA), children constitute a greater proportion of the population and may be more vulnerable for several other reasons as the prevailing malnutrition, HIV, tuberculosis which contribute to the occurrence of severe respiratory tract infection $[5,6]$. In addition, the other risks are linked to the meager resources allocated to the health sector, the priority that families sometimes give to adult with health problems and low vaccines coverage which exposes SSA children to several diseases that can reduce their immunity [7-9].

To our knowledge, no severe form of Covid-19 in children has been described in Central Africa. Until now, rare cases of severe covid-19 in children living in SSA have been described, especially in South Africa $[10,11]$. In general, these children had progressed well despite a sometimes serious clinical picture. This clinical case concerns an infant of 4 months and 8 days, who presented a severe form of Covid-19. Apart from malaria and anemia, no other co-morbidity was associated. The importance is to attract the attention of pediatricians so as not to overlook such cases despite their rarity. The CT images as well as the management strategy are also discussed. The requirement for informed consent was obtained from the patient's parents.

\section{Case presentation}

A 4-month and 8 days -old male infant admitted on $4^{\text {th }}$ August 2020 with a severe distress respiratory. He was transferred from a private hospital. The story of the disease started by fever, dyspnea and cries 9 days before. He received tea and orange juice because parents suspected abdominal pain also because of cries. His condition was not improved after receiving these drugs from family members at home. He was admitted at a private hospital where he was treated with gentamicin, amoxicillin, vitamin $\mathrm{C}$, Argyrol nose drops and received also blood transfusion because hematocrit was low $(21 \%)$. The private hospital transferred the infant at University hospital because no improvement was observed. At admission, respiratory rate was high (60 cycles/minute) with tachycardia at $166 /$ minute. The weight was $5 \mathrm{Kg}$ which was normal for the age and the birth weight was 2800 grammes. The lung auscultation reported under crakes in the two lungs. Oto-Rhino-Laryngology exam was normal. After all the physical exam, the pediatric team suspected a severe Bronchopneumonia. Because of local COVID 19 score (table 1) with the value of 4/26 (fever: 2 and distress syndrome: 2), COVID 19 was suspected also. The diagnosis was confirmed by Reverse Transcriptase Polymerase Chain Reaction (RT-PCR). So, the children has been 
admitted at the Covid treatment center. COVID 19 IgM and IgG

antibodies were nor performed.

\begin{tabular}{|c|c|c|}
\hline SYMPTOMS & EXPLANATION & MARKS \\
\hline Do you have a dry cough? & $\begin{array}{l}\text { The Patient has a persistent cough? or an increase in his usual } \\
\text { cough if it is chronic }\end{array}$ & 2 \\
\hline Do you have fever? & Temperature $>=37,7 \mathrm{C}$ & 2 \\
\hline Do you have headache? & An unusual headache & 1 \\
\hline Do you have difficulty breathing & $\begin{array}{l}\text { The Patient feels unusually short of breath, He has trouble } \\
\text { breathing }\end{array}$ & 2 \\
\hline Do you have unusual fatigue & $\begin{array}{l}\text { An unusual physical Asthenia, without obvious causes which } \\
\text { prevent the patient from giving himself to his usual activities }\end{array}$ & 1 \\
\hline Do you have stiffness & The Patient feels muscles pains and or the pain in his joints & 1 \\
\hline Do you have sore throat & A throat irritation with no other obvious cause & 1 \\
\hline Have you lost the taste in food? & $\begin{array}{l}\text { The Patient cannot longer recognize the taste of the food } \\
\text { Example: Rice and vegetables has no flavor }\end{array}$ & 2 \\
\hline Have you lost your sense of smell & The patient no longer smells odor without nasal congestion & 2 \\
\hline Do you haven diarrhea? & Diarrhea in the last 24hours & 1 \\
\hline Do you have nausea and vomiting & & 1 \\
\hline $\begin{array}{l}\text { Have you been in in Country touched by } \\
\text { Covid19 in the last 14days }\end{array}$ & Cfr List of the most affected country & 2 \\
\hline $\begin{array}{l}\text { Have you been in touch with someone who } \\
\text { came from a Country touched by Covid19 }\end{array}$ & Cfr List of the most affected country & 2 \\
\hline $\begin{array}{l}\text { Have you been in touch with someone who } \\
\text { suffer of Covid19 }\end{array}$ & $\begin{array}{l}\text { The patient has been in direct contact with a probable case of } \\
\text { Covid19? Example: A love from whom we have been sick guard, A } \\
\text { friend in which we had direct contact, A patient that we treated }\end{array}$ & 2 \\
\hline $\begin{array}{l}\text { Have you been in touch with someone who } \\
\text { has the following symptoms : fever, dry } \\
\text { cough and difficulty breathing }\end{array}$ & If the patient has been in contact with a suspect case of Covid19 & 2 \\
\hline Pathological chest CT scan & $\begin{array}{l}\text { Presence of CT signs of covid19:bi-basal and peripheral frosted } \\
\text { glass crazy paving }\end{array}$ & 2 \\
\hline Total & & 26 \\
\hline
\end{tabular}

Table 1: Covid 19 local diagnostic probability score of draw

If the triage score is low, clinical suspicion of covid19 infection is retained

\section{Conclusion:}

1. Weak Probability $<4$

2. $\quad$ Suspected case $\geq$

Laboratory tests showed an elevated white blood cell (WBC: $22.800 / \mathrm{mm} 3$ ) count and neutrophil count (68\%), low C-reactive protein
(CRP: 4mg/L), and elevated total and direct bilirubin (respectively 3.09 and $2.44 \mathrm{umpl} / \mathrm{L}$ ). Alanine aminotransferase (ALAT), and aspartate amino transaminase (ASAT) were elevated (95.3 and 64.46 U/L In addition, Blood gaz showed low Pao2 (Table 2). The chest CT showed pure Ground Glass Opacities (GGOs), located under pleural at posterior segment VI of upper right lobe (Fig1 and fig3) and hilar bilateral patches along with Broncho vascular bundles (Fig2).The test for the mother was positive for COVID 19 without any manifestations

\begin{tabular}{|c|c|c|}
\hline Parameters & Value obtained & Normal value \\
\hline $\begin{array}{l}\text { Hematology } \\
\mathrm{Hb} \\
\mathrm{GB} \\
\mathrm{FL} \\
\mathrm{GE} \\
\text { Réserve alcaline } \\
\text { Gaz in blood } \\
\mathrm{PH} \\
\text { pCO2 } \\
\text { pO2 } \\
\text { cHCO3 } \\
\mathrm{Be}(\text { ecf) } \\
\text { cSO2 } \\
\text { Biochemestryb } \\
\text { Bili total } \\
\text { ALAT }\end{array}$ & $\begin{array}{l}11,7 \mathrm{~g} / \mathrm{l} \\
22.800 / \mathrm{mm} 3 \\
\mathrm{~N} 68 \% \mathrm{~L} 32 \% \\
\text { tropho }+ \\
20 \mathrm{mmol} / 1 \\
7,457 \\
33,3 \\
49,0 \\
23,6 \\
-0,3 \\
86,7 \\
3.09 \\
95.73\end{array}$ & $\begin{array}{l}\text { 11-13g.dl } \\
\text { 4.000-12000:mM3 } \\
\text { FL60 L30M8E2B1 } \\
\text { Negative } \\
\text { 11-26mmol/l } \\
\text { (A: 7,35-7,45/ V: 7,32-7,43) } \\
\text { (A: } 35-48 / \mathrm{V}: 41-51) \mathrm{mmHg} \\
\text { (A: } 83-108) \mathrm{mmHg} \\
\text { (A: } 21-28 / \mathrm{V}: 22-29) \mathrm{mmol} / \mathrm{l} \\
(-2-+3) \mathrm{mmol} / \mathrm{l} \\
\text { (A: } 94-98) \% \\
0.20-1.80 \mathrm{Umol} / \mathrm{L} \\
\text { 10.00-47.OOU/L }\end{array}$ \\
\hline
\end{tabular}




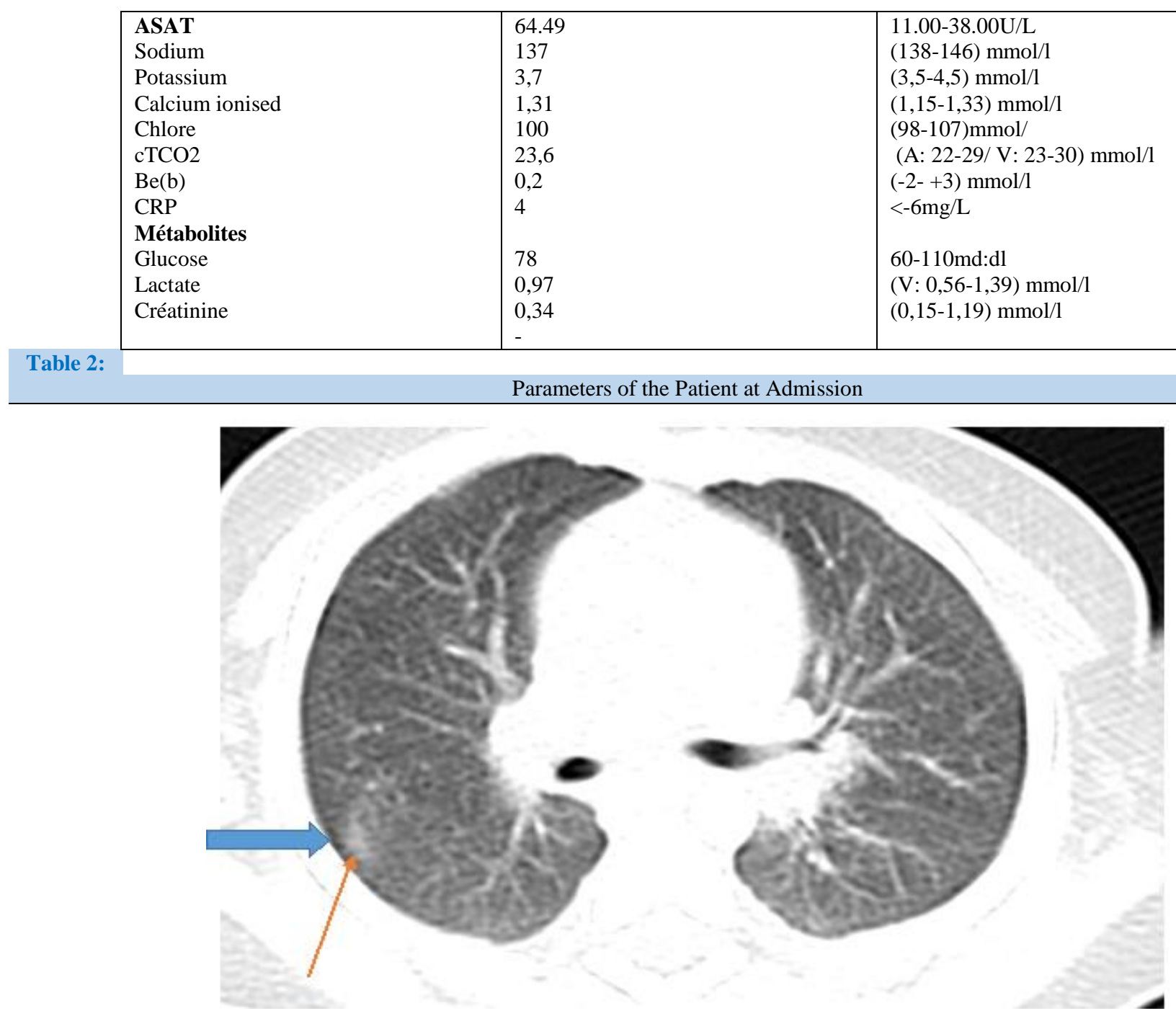

Figure 1: CT scan Image in axial cup shows a large Ground Glass Opacities under pleural segment VI

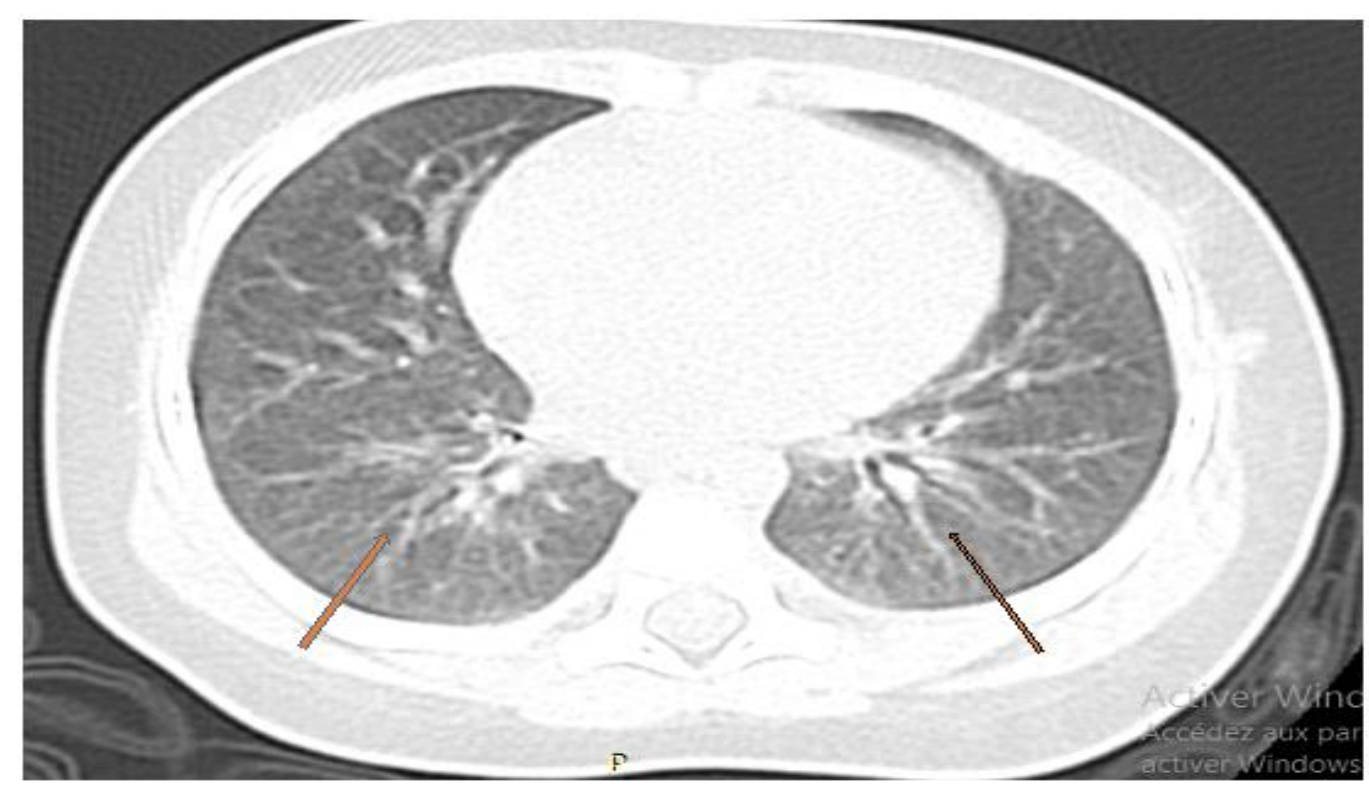

Figure 2: axial cup in parenchyme window: showing patches along with Broncho vascular bundles 


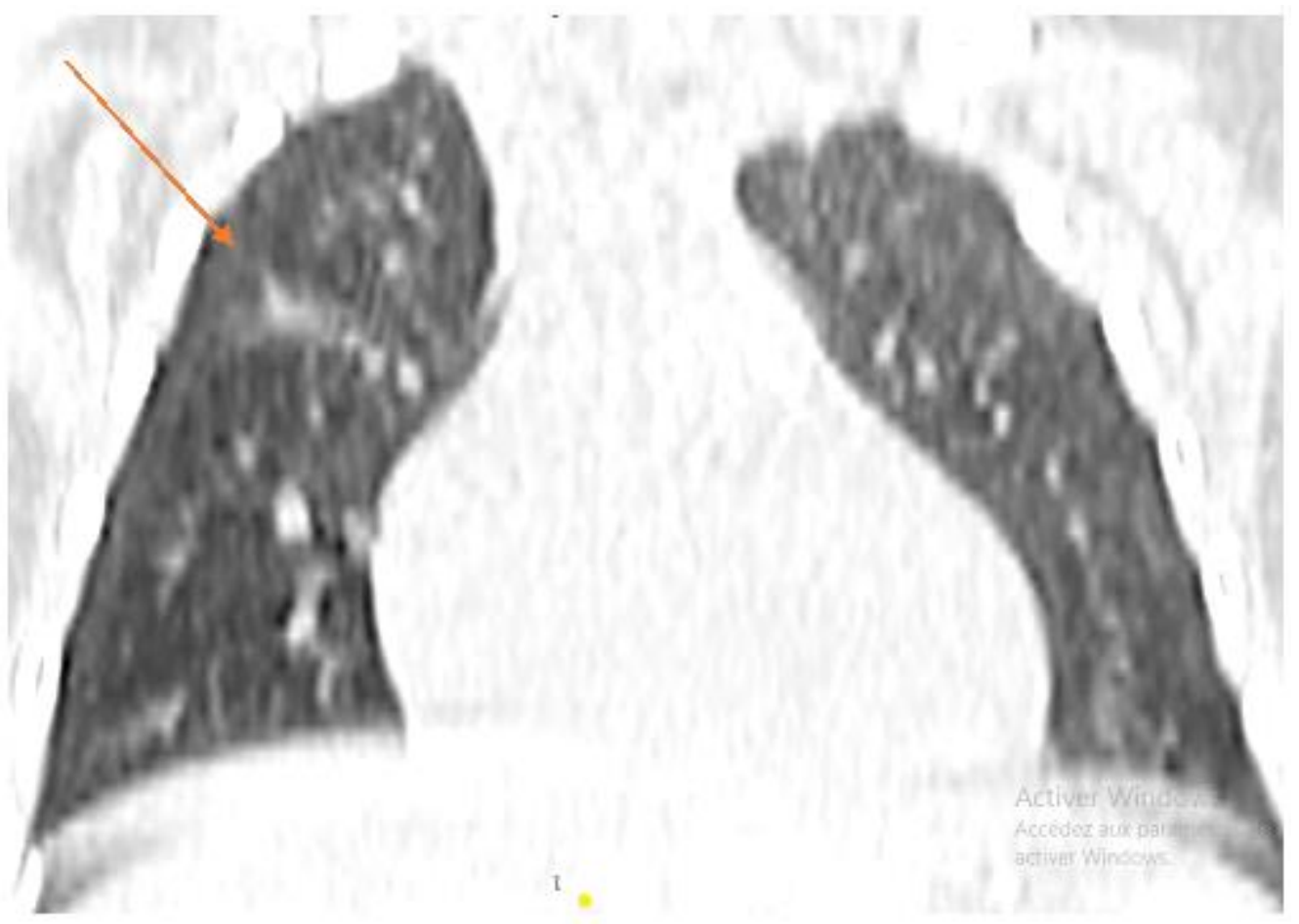

Figure 3: CT scan in coronal cup showing pure ground glass opacities

\section{Diagnosis:}

We concluded to: SARS -Cov-2 in infant 4 months and 8 days, sepsis with pneumopathy origin and malaria with hemolytic anemia.

The infant was treated according to the national policy of COVID 19 treatment in Democratic Republic of Congo with Azithromycin (10mg/Kg once per day for 5 days), chloroquine $(10 \mathrm{mg} / \mathrm{Kg}$ once per day for 5 days) Lovenox ( $0.025 \mathrm{cc}$, twice per day for 7 days), Vitamin C ( $5 \mathrm{ml}$, twice per day for 7 days) and Zinc (2.5ml twice per days for 7 days. Malaria was treated with quinine (5 drops, three time per day for 7 days: $3 X 10 \mathrm{mg} / \mathrm{kg}$ of Quinine per day for 7 days). He received intermittent oxygen using extractor 5 liter/minute for 3 days. The child was treated during 8 days at Kinshasa University Hospital CTC and was discharged on 17 August 2020

\section{Discussion}

This rare case in the context of Covid-19 is very illustrative. The initial table evokes malaria, but thanks to the attention of pediatricians (based on the warning signs), the in-depth examinations have made it possible to diagnose Covid-19.

Basically, children have often milder disease than adults. In COVID-19 children, severity is classified as mild (asymptomatic or subclinical), normal, severe, and critical [12]. Mostly in children, cases are mild or normal severity and case fatality rate is very low. In children, the milder course of the disease results to their immature immune system, which does not overreact to the virus, but the reasons why disease tends to be less severe in children requires more researches for best evidence.

It is observed and reported that children usually have, atypical, mild and asymptomatic disease with only fever (50\%) and cough (38\%) which are the main presenting complaints [9]. Two other children admitted in our CTC had no symptoms. They were just tested positive after family screening because parents were COVID 19 positive. Our patient presented fever and severe distress syndrome using oxygen treatment for the management of the case. According to the severity of the diseases in children, studies [13] found that children may develop also severe disease and lead to worse outcome, especially when diagnosis is delayed because of atypical presentations at the beginning of the disease. Our patient, finally developed severe clinical features with severe distress. So far, many questions remain without response, especially the reason which can explain the severity of the disease in our infant. Association with malaria could explain the severity of the disease? The first pediatrics severe case was reported in Wuhan. He was 13-month-old boy without previous comorbidity and he developed shock, acute respiratory distress, and renal failure [14]. Fortunately, our child did not develop shock and renal failure. Risk factors for severe disease in children are not well understood because no more cases are reported. Laboratories figures can be different compared to adults [15].In our case, whole White Blood Cells and neutrophil were increased but CRP was decreased. ALAT and ASAT were elevated

It is necessary to thing to other infectious diseases of the lungs in case of atypical features at chest CT for differential diagnosis, including bronchopneumonia, mycoplasma pneumonia, and seasonal influenza. CT scan, basically in adults found that injuries could involve all lobes. Injuries in the upper lobes are more severe and there are 4 categories of CT findings described in adults:(a) Pure Ground-Glass Opacities (GGOs), (b) pure consolidation, (c) both GGOs and consolidation; and(d) small nodules and patches along with Broncho vascular bundles, similar to bronchopneumonia [10]. The chest CT scan of the infant found Pure Ground-Glass Opacities (GGOs) under pleural at posterior segment of upper lobe of right lung and patches along with Broncho vascular bundles at the 2 hiles. These images observed in our children can explain the severity of the disease.

Mostly in children, the CT features are different compared to adults [11].The GGOs are regularly present in adult. The distribution of injuries is located frequently in the peripheral and posterior areas of both lungs [12].

The infant was treated according to the national policy of COVID 19 treatment .This protocol was approved by the concertation between 
University and the technic secretariat of COVID19 riposte. Corticoids were not given to our patient because not included in our protocol in that moment. The evolution were very good with this protocol and the infant was discharged after 8 days of treatment.

In conclusion, severe cases of SARS-COV-2 exist in pediatrics population. Pediatricians should be aware to check children with severe distress. By this way, we can diagnose early and treat correctly children infected by Coronavirus.

\section{Competing interest}

The authors declare that they have no competing interests.

\section{Authors" contributions}

BJM, MJRR, MIK, MMM, ALP, MFM and LVV conceived, designed, deployed and wrote directed the case report study MJK, NBM, OGO, MNM received the patient sat the Centre of Covid Treatment and treated the infant.

\section{LMT and TFT performed the CT scan exam.}

\section{Acknowledgments}

The authors thank NGO ALIMA for the support received about the treatment of patients with VOVID19. They thanks INRB for the logistics support.

\section{References}

1. ZhonghuaLiu Xing Bing Xue Za Zhi. (2020) Epidemiology Work in GroupforNCIPE pidemic Response, Chinese Center for Disease Control and Prevention. The epidemiological characteristics of an outbreak of 2019 novel coronavirus diseases (COVID-19) in China. Article in Chinese. 41(2):145151.

2. Docherty AB, Harrison EM, Green CA,et al. Features of 16,749 hospitalised UK patients with COVID-19 using the ISARIC WHO Clinical Characterisation protocol.

3. CDCCOVID-19 Response Team. (2020) Corona virusdisease 2019 in children-United States, February12-April 2, 2020. MMWR Morb Mortal Wkly Rep. 69(14):422-426.
4. National Institute for Public Health and the Environment. Children and schools. Accessed July20, 2020.

5. COVID-19 National Incident Room SurveillanceTeam. COVID-19, Australia: epidemiology report 13(reporting week to 23:59 AEST 26 April 2020). Commun Dis Intell.

6. Yang Y, Lu Q, Liu M, et al. (2019) Epidemiological and clinical features of the 2019 novel coronavirus outbreak in China.

7. Wang XF, Yuan J, Zheng YJ, et al. (2020) Clinical and epidemiological characteristics of 34 children with 2019 novel coronavirus infection in Shenzhen. Zhonghua Er Ke Za Zhi. 58:E008

8. Ricardo F, Ajelli M, Andrianou X, et al. (2020) Epidemiological characteristics of COVID-19 cases inItaly and estimates of the reproductive numbers one month into the epidemic. medRxiv.

9. Zhonghua Liu Xing Bing Xue Za Zhi. (2020) Special Expert Group for Control of the Epidemic of Novel Coronavirus Pneumonia of Chinese Preventive Medicine Association An update on the epidemiological characteristics of novel coronavirus pneumonia (COVID-19). 41:139-44.

10. Ma JH, Shao JB, Wang YJ, et al. (2020) High resolution CT features of novel coronavirus pneumonia in children. Chin $\mathrm{J}$ Radiol. 54:1005-1201.

11. Lei J, Li J, Li X, et al. (2020) CT Imaging of the 2019 novel coronavirus (2019- nCoV) pneumonia. Radiology. 200236.

12. The Society of Pediatrics, Chinese Medical Association; the Editorial Board, Chinese Journal of Pediatrics. Recommendations for the diagnosis, prevention and control of the 2019 novel coronavirus infection in children (first interim edition). Chin J Pediatr, 2020 Feb 9 58:E004.

13. Choi SH, Kim HW, Kang JM, et al. (2020) Epidemiology and clinical features of coronavirus disease 2019 in Children. Clin Exp Pediatr. 63:125-132.

14. Chen F, Liu ZS, Zhang FR, et al. (2020) First case of severe childhood novel coronavirus pneumonia in China. Zhonghua Er Ke Za Zhi;58:179-182.

15. National Health Commission of the People's Republic of China Diagnosisand treatment protocols of pneumonia caused by a novel coronavirus.Beijing: National Health Commission of the People's Republic of China. 2020.
This work is licensed under Creative Commons Attribution 4.0 License

\section{To Submit Your Article Click Here: Submit Manuscript}

DOI: $10.31579 / 2692-9406 / 038$
Ready to submit your research? Choose Auctores and benefit from:

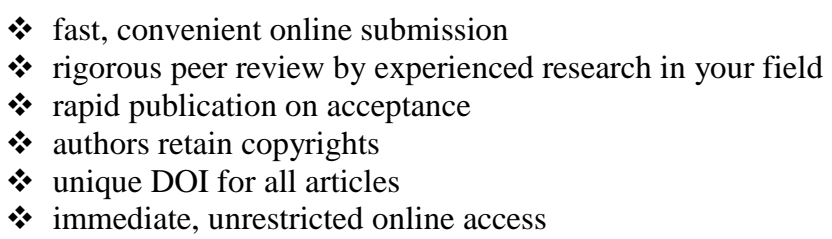

At Auctores, research is always in progress.

Learn more www.auctoresonline.org/journals/biomedical-research-andclinical-reviews- 